\title{
CUADERNOS
}

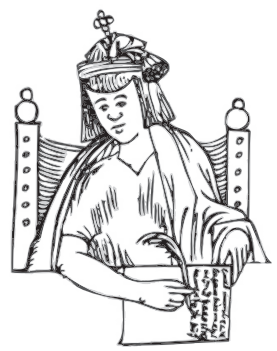

\section{APROXIMACIÓN A LA HISTORIA DE LOS JUDÍOS DE NANCY (FRANCIA) DESPUÉS DE LA OCUPACIÓN ALEMANA, 1940-1944}

Matilde Morcillo*

RESUMEN: El objeto de este trabajo es hacer una aproximación a las comunidades judías de Nancy después de la ocupación alemana durante la Segunda Guerra Mundial, a través de un cuestionario muy interesante hallado en los archivos del Centro de Documentación Judía Contemporánea de París, que nos ha permitido reconstruir la historia de los judíos de Nancy, deteniéndonos principalmente en la evolución de la población judía, el número de arrestados y deportados y los daños causados en los edificios religiosos, entre otras cosas, lo que ha supuesto todo un acontecimiento al sacar a la luz una información inédita muy valiosa, habida cuenta de la casi inexistencia de estudios sobre los judíos de Nancy, ni siquiera en relación con los judíos de Francia en general.

Palabras Clave: judíos, Nancy, Francia, ocupación alemana, 1940-1944.

\section{APPROXIMATION TO THE HISTORY OF THE JEWS OF NANCY (FRANCE) AFTER THE GERMAN OCCUPATION, 1940-1944}

ABSTRACT: The purpose of this work is to make an approximation to the Jewish communities of Nancy after the German occupation during World War II through a very interesting questionnaire found in the archives of the Center for Contemporary Jewish Documentation in Paris, which has allowed us to reconstruct the history of the Jews of Nancy, I focus mainly on the evolution of the Jewish population, the number of arrested and 


\begin{abstract}
deported Jews, and the damage caused to religious buildings, among other things, which has been quite an event in bringing to light very valuable unpublished information, given the lack of studies on the Jews of Nancy, not even in relation to the Jews of France in general.
\end{abstract}

KEYWORDS: Jews, Nancy, France, German occupation, 1940-1944.

Recibido: septiembre 2018

Aceptado: marzo 2019

\title{
Introducción
}

\begin{abstract}
A
empezar la Segunda Guerra Mundial con la invasión de Polonia por parte de Alemania el 1 de septiembre de 1939, Francia e Inglaterra, aliadas de Polonia, declaraban la guerra a Alemania y ésta respondía con la ocupación de Francia en junio de 1940. Un mes después, los franceses se rendían y firmaban un armisticio. De esta forma, el país se dividió en dos partes, el norte de Francia, incluyendo París, fue la zona ocupada, quedando bajo el control de las fuerzas alemanas, mientras que en el sur, la zona no ocupada, el general Philippe Pétain, héroe de la Primera Guerra Mundial, estableció un nuevo gobierno en la ciudad de Vichy que colaboraría con los alemanes ${ }^{1}$. Pero el general Charles De Gaulle, que se oponía a que este gobierno colaborara con los nazis, se refugió en Gran Bretaña, desde donde dirigió a un grupo de franceses exiliados para conseguir liberar a Francia de la tiranía de los alemanes y del gobierno colaboracionista de Vichy, el cual creó la Milicia con el apoyo de las autoridades alemanas para perseguir a los judíos².
\end{abstract}

Finalmente, los aliados desembarcaron en Normandía el 6 de junio de 1944 y liberaban a Francia dos meses después. El general De Gaulle entraba victorioso en el país y los dirigentes del gobierno de Vichy huían.

Según $\mathrm{Avni}^{3}$, en 1940 habrían estado viviendo en Francia aproximadamente 35.000 judíos. Con la ocupación, muchos de ellos habían huido de la persecución nazi. Como ya se ha dicho, los alemanes invadieron Francia en junio de 1940,

Klarsfeld, 2001; Avilés, 1989, pp. 227-239; Morcillo, 2016.

2 Gildea, 2016. También puede verse sobre la Milicia: https://www.abc.es/internacional/20150612/ abci-resistencia-francesa-mito-guerra-201506111945.html. Consultado el 3 de enero de 2019; https://www.enlacejudio.com/2018/11/18/la-francia-de-vichy-capital-del-colaboracionismo-conlos-nazis/. Consultado el 8 de enero de 2019.

3 Avni, 1982, p. 81. 
ocupando la capital. Durante las primeras semanas, las autoridades alemanas se mostraron tolerantes hacia los judíos franceses, aunque esto duraría poco tiempo. También los judíos sefardíes, de momento, estuvieron exentos de cualquier medida ${ }^{4}$. El 27 de septiembre de 1940 los alemanes promulgaban la primera Ordenanza en la zona ocupada, según la cual todos los judíos deberían inscribirse en una Prefectura de policía para que se estampara en sus documentos la palabra judío. No conforme con esto, el gobierno de Vichy emitió el 3 de octubre de 1940 el Estatuto de los Judíos, por el que los judíos se distinguían del resto de la población ${ }^{5}$. El Estatuto reconocía como judíos a todos los que tuvieran al menos tres abuelos pertenecientes al pueblo judío. A partir de dicho Estatuto, les fue prohibido acceder a las administraciones públicas, ser médicos o trabajar en actividades artísticas como prensa, teatro y cine. A los que tuviesen negocios se les obligaba a colocar en el escaparate un letrero amarillo que rezase Entreprise Juive (Empresa Judía).

Todos los asuntos entre judíos y franceses se harían a través del Consistorio de París que dirigía el judío Isaie Schwarz ${ }^{6}$. Poco después, el 18 de octubre, se publicaba la segunda Ordenanza que afectaba a las empresas judías, y así, sucesivamente, ordenanza tras ordenanza, se iría discriminando a los judíos hasta la deportación y la solución final'

\section{Historia de los judíos de Nancy}

Nos hubiera gustado hacer una introducción sobre cómo vivieron las comunidades judías de Nancy durante la ocupación alemana, pero, desgraciadamente, no nos ha sido posible habida cuenta de que no hemos encontrado información al respecto, solamente la contenida en el cuestionario, base fundamental del presente trabajo.

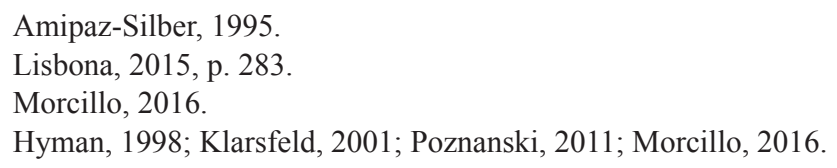




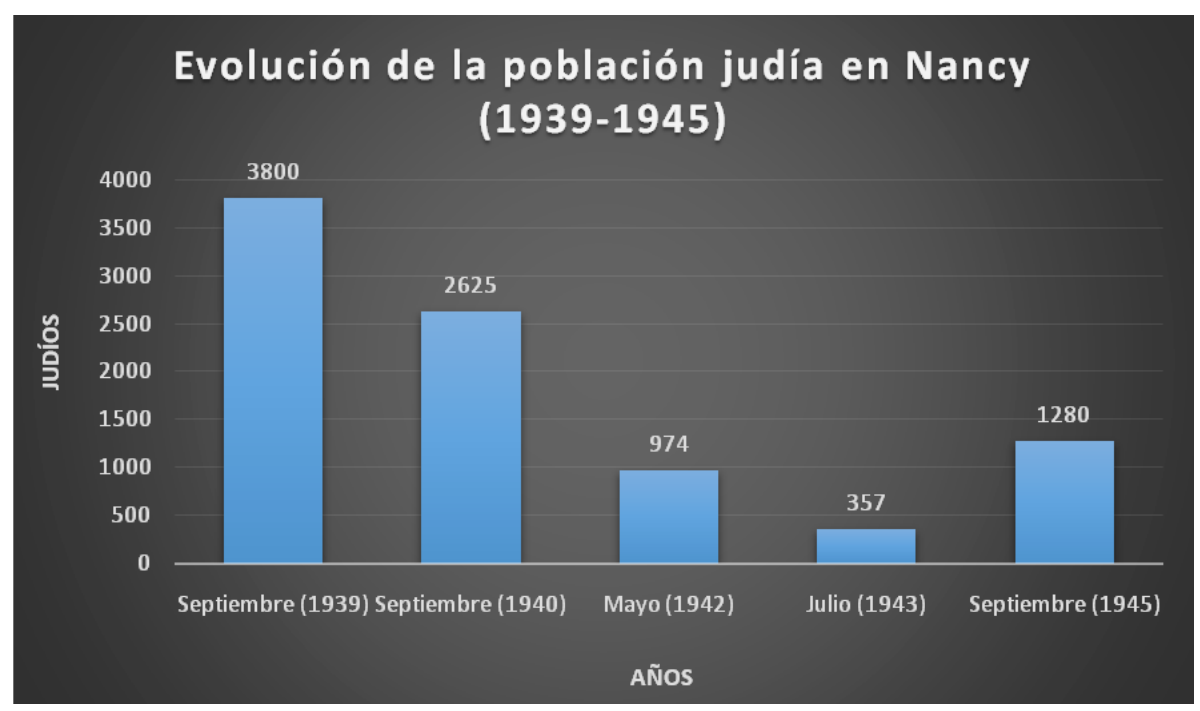

1. Evolución de la población

Fuente: Elaboración propia

Según el cuestionario hallado ${ }^{8}$, al comenzar la guerra, el 1 de septiembre de 1939, en Nancy había unos 3.800 judíos repartidos en dos comunidades bien diferenciadas, la comunidad compuesta por judíos casi exclusivamente franceses y una comunidad mucho más grande de origen extranjero residente en Nancy, la mayor parte de nacionalidad polaca y rusa. En la primera comunidad había alrededor de 1.200 personas; la comunidad polaca contaba con $2.500^{9}$. Es decir, un total de 3.700 judíos, pero que si se tienen en cuenta a las personas que no pertenecían a ninguna comunidad y que eran poco numerosas, cerca de un centenar, ya suman los 3.800. Esta cifra forma parte de los 35.000 judíos que había en Francia en 1940, según Avni ${ }^{10}$. En este cómputo podemos decir que los judíos sefardíes eran alrededor de 3.000 , de ellos 2.000 estaban inscritos

8 El cuestionario ha sido traducido del francés al español y fue realizado por Arthur Willard en febrero de 1946 en Nancy, al parecer, a petición del Congreso Judío Mundial para evaluar la situación de las comunidades judías tras la ocupación alemana durante la Segunda Guerra Mundial. Archivo Centro Documentación Judía Contemporánea, París, C.D.J.C., XX-13.

9 Willard, 1946, p. 1.

10 Avni, 1982. 
en el consulado de España en París y otros 1.000 en los distintos consulados de la zona de Vichy ${ }^{11}$.

Con la entrada de los alemanes en Francia en junio de 1940, muchos judíos habían salido de Nancy, también lo hicieron del resto del país dirigiéndose, una mayoría de ellos, hacia España ${ }^{12}$. Como ya se ha dicho, el 27 de septiembre de 1940, las autoridades alemanas aprobaron la primera ordenanza que obligaba a los judíos a inscribirse en una Prefectura. En ese momento, el número de judíos de Nancy censados era de 2.625, lo que nos hace suponer que más de 1.000 habían huido de la ciudad, y que más lo seguirían haciendo.

A partir del 21 de octubre de 1940, la Feldkommandantur, agrupación del Estado Mayor alemán, ordenaba al Prefecto que se pusiera en los carnés de identidad de los judíos la mención "judío o judía” con sello rojo. Sería a partir de esta medida, cuando podemos decir que salió de Nancy el mayor número de judíos. Prueba de ello es que, cuando se publicó la ordenanza del 8 de mayo de 1942 que obligaba a los judíos a llevar la estrella amarilla ${ }^{13}$, en Nancy solo se distribuyeron 974 insignias, lo cual quiere decir que en ese momento la población judía era de 974 personas. A ello habría contribuido también, quizá, el altavoz que los alemanes habían instalado en un punto central de la ciudad y que durante todo el día vertía injurias sobre los judíos acusándoles de ser los instigadores de la guerra.

Con el avance de la contienda, las medidas contra los judíos en la zona ocupada de Francia se fueron endureciendo; ello explica que en julio de 1943 solo quedaban en Nancy 357 judíos de los 3.800 que había al inicio de la guerra ${ }^{14}$. Por su parte, Job ${ }^{15}$ dice que en 1944 en Nancy había 280 familias judías. Sin embargo, llama la atención sorprendentemente cómo a primeros de septiembre de 1945, una vez terminado el conflicto, el número de judíos de Nancy asciende a 1.280, de los cuales, 600 eran judíos franceses, y 680, de origen extranjero, fundamentalmente polacos, lo cual pone de manifiesto que casi un tercio regresó, salvándose de la opresión nazi, habida cuenta de que pudieron salir a tiempo de la zona ocupada.

11 Morcillo, 2016.

12 Rother, 2005, pp. 144-148.

13 Véase anexos, p. 19.

14 Willard, 1946, p. 1.

15 Job, 1997, p. 99. 
Judios prisioneros de guerra, alistados en las fuerzas francesas y muertos durante la ocupación

A pesar de la búsqueda, ha resultado muy difícil conocer el número de judíos prisioneros de guerra dada la escasez de información hallada sobre ello en el mencionado cuestionario, únicamente se podría decir de forma aproximada que hubo alrededor de unos 50 prisioneros.

Por otro lado, no se ha encontrado ninguna documentación en la Prefectura de Nancy que pueda decir los judíos que se alistaron en el ejército; sin embargo, en la comunidad judía polaca de Nancy hubo 68 voluntarios en el ejército, que en las Fuerzas Francesas del Interior se alistaron 105, y que parecía ser que muchos judíos de Nancy habían cumplido servicio, tanto de oficiales como de simples soldados, en el ejército de África, pero, desgraciadamente, no se disponía de cifras precisas en ese momento; no ocurre lo mismo sobre los muertos, pues hubo dos en cautividad, una madre y su hija, tres caídos en la resistencia (maquis) y dos que perecieron en la liberación de Francia ${ }^{16}$. Ahora bien, estas cifras no solo se refieren a la ciudad de Nancy, sino a diversas regiones de la zona no ocupada, donde los judíos de Nancy se habían refugiado.

\section{Número de judios deportados de Nancy}

Además de los arrestos individuales hechos por la Gestapo, también hubo en Nancy varias redadas de judíos de origen extranjero: el 19 de julio y el 9 de octubre de 1942 y el 23 de febrero de 1943. Hay que señalar que en París las redadas empezaron antes: entre el 20 y el 25 de agosto de 1941 se produjo la segunda redada y fueron detenidos 5.784 judíos varones de 18 a 50 años ${ }^{17}$, entre los que había 14 judíos sefarditas que fueron liberados por el Cónsul General de España en París, Bernardo Rolland, el 3 de abril de $1942^{18}$. Si bien, la redada del Velódromo de Invierno del 16 al 17 de julio de 1942 está considerada como la más importante realizada en Francia contra los judíos durante la Segunda Guerra Mundial ${ }^{19}$.

16 Willard, 1946, p. 2.

17 Lisbona, 2015, 287; Klarsfeld, 1978.

18 Morcillo, 2016.

19 Rother, 2005; Lisbona, 2015. Sobre la redada de julio de 1942 puede verse también: http://www.lecturasdelholocausto.com/uploads/1/0/9/6/10969104/guía_velódromo_de_invierno. pdf. Consultado el 29 de diciembre de 2018; https://www.enlacejudio.com/2017/07/16/laredada-del-velodromo-invierno/. Consultado el 29 de diciembre de 2018; https://elpais.com/ diario/2010/03/18/cultura/1268866802_850215.html. Consultado el 29 de diciembre de 2018. 
En cuanto a Nancy, hay que decir que si en la primera redada de 19 de julio de 1942 había una lista de 350 personas para detener, cuando se presentó la Gestapo acompañada de la policía y de los gendarmes no pudieron encontrar nada más que a 32 judíos, ya que fueron muchos los que habían abandonado la ciudad y otros habían sido prevenidos, bien por policías y gendarmes o por otras vías. El hecho es que entre las tres redadas que hubo, como ya se ha dicho anteriormente, fueron arrestados en Nancy un total de 130 judíos de origen extranjero, aunque según la comunidad judía polaca fueron 550 (460 judíos y 90 políticos). El excedente de 130 ha sido tomado en las diversas regiones de la zona libre.

Mención especial requiere la gran redada de 2 de marzo de 1944 en Nancy, en el curso de la cual fueron arrestados aproximadamente 230 judíos de origen francés. Por ello, si se tienen en cuenta a los judíos franceses precedentemente arrestados, el número de judíos galos deportados fue de 252 aproximadamente. La Gestapo había dejado en Nancy una cuarentena de personas enfermas o impotentes, pero que fueron detenidas posteriormente el 13 de julio de $1944 \mathrm{y}$ transferidas al Centro de detención de Écrouves ${ }^{20}$, de donde serían liberadas a principios de septiembre por las tropas americanas.

En la citada redada del 2 de marzo, no podemos pasar por alto, por el significado que tuvo, la actuación del rabino Paul Haguenauer ${ }^{21}$, Gran Rabino de Nancy desde 1919, que desde el armisticio de 22 de junio de 1940 que ponía fin a las hostilidades entre los representantes del Tercer Reich alemán y los del gobierno francés del General Pétain en el contexto de la guerra, indiferente al peligro que podía correr por su muy delicada salud, por la fatiga y las privaciones, estaba realizando verdaderos esfuerzos ante las autoridades locales, tanto para socorrer a los judíos refugiados de Alsacia y Lorena, como a los de Nancy, siempre que iban a pedir su ayuda, arriesgando en ocasiones su vida. A decir verdad, muchas personalidades de Nancy le habían advertido del peligro que corría, pues desde hacía tiempo estaba siendo vigilado por la Gestapo, por lo

20 Écrouves: población del departamento de Meurthe-et-Moselle.

21 Sobre el Gran Rabino Paul Haguenauer véanse: Albert Manuel, Paul Haguenauer. Grand Rabbin de Nancy 1871-1944; http://judaisme.sdv.fr/histoire/rabbins/haguen/ index.htmFrançoise Job, "Paul Haguenauer, grand rabbin (Bergheim, Haut-Rhin, 11 janvier 1871 - Auschwitz, avril 1944)", Archives Juives 2002/2 (Vol. 35), pages 145 à 148. Renée Poznanski, Jews in France During World WarII https://books.google.es/ books?id=MzAhHLLtsDcC\&dq=rabino + paul + haguenauer,+ francia $\& \mathrm{hl}=\mathrm{es} \&$ source $=\mathrm{gbs}$ navlinks_s pp. 257-258. Consultado el 14 de enero de 2019; Françoise Job, Les Juifs de Nancy du XIIe au XXe siècle [compte-rendu] Martine Cohen, Archives de Sciences Sociales des Religions, 1997, p. 99. Consultado el 10 de febrero de 2019. 
que le habían aconsejado abandonar la ciudad, pero siempre se negó a ello. Es más, en muchas ocasiones había dicho: "Yo permaneceré en Nancy mientras haya un judío en Nancy"22.

Sirva de ejemplo lo que ocurrió un mes antes de la redada de 2 de marzo de 1944, cuando la Gestapo fue a casa de un funcionario de la sinagoga para detenerlo, conocedora de que éste había guardado una parte de sus muebles en casa de un amigo. Dicho funcionario logró escapar mientras interrogaban a su mujer, pero la policía, al darse cuenta, decidió detener a la mujer en lugar de a su marido.

El Gran Rabino, que vivía en el mismo inmueble, habiendo oído gritos se dirigió al apartamento donde se desarrollaba la escena y tras una conversación con la Gestapo la mujer fue puesta en libertad provisionalmente. Ocho horas después, cuando parecía que se había resuelto el caso, el Gran Rabino recibió la visita de un oficial de la Gestapo, informándole que si el funcionario huido no se presentaba, tomarían a 30 rehenes en la comunidad. El Gran Rabino habló durante bastante tiempo con el oficial, tratando de hacerle ver la injusticia de semejante medida, habida cuenta de que la comunidad no era responsable de la huida del israelita y, de momento, no hubo respuesta a la amenaza; sin embargo, tres semanas más tarde se producía la ya citada redada del 2 de marzo, aunque, según se dijo, no existía relación entre este incidente y la redada, puesto que, por la misma fecha, hubo operaciones idénticas en otras comunidades de la región del Este de Francia, si bien, parece ser que el rabino y su esposa fueron arrestados por la Gestapo el 3 de marzo de 1944, detenidos en Écrouves y conducidos al campo de Drancy desde donde fueron deportados a Auschwitz en abril de 1944, siendo asesinados poco después.

En definitiva, para conocer el número de judíos detenidos y deportados de Nancy, como primero fueron internados en Écrouves, un documento elaborado por el director del Centro, aunque no da cifras ni nombres de personas ni del lugar de origen, sí señala que en Écrouves, durante la ocupación alemana, estuvieron 701 hombres, 873 mujeres y 304 niños. Se trataba, sin ninguna duda, de judíos arrestados en Meurthe-et-Moselle, en La Meuse y en Les Vosges.

También en la primera redada de judíos extranjeros (19 de julio de 1942), la Gestapo, a petición de la comunidad, había colocado en el asilo de ancianos de la calle de Villers, bajo la vigilancia de los alemanes, a una treintena de niños 
separados de sus padres. Poco tiempo después fueron deportados, excepto tres o cuatro niños que pudieron ser puestos a salvo por familias católicas ${ }^{23}$.

\section{Actitud de la policía y de las autoridades}

Las redadas de judíos de origen extranjero habían sido llevadas a cabo por la Gestapo acompañada de policías y gendarmes franceses. En general, la actitud de las autoridades administrativas y policíacas fue más bien pasiva. Algunos gendarmes y policías previnieron de la operación que se preparaba a ciertas familias judías que ellos conocían. Como era de suponer, la noticia corrió como un reguero de pólvora de familia en familia, lo que explica que en la redada del 9 de julio de 1942 los alemanes no encontraron nada más que a treinta y dos judíos de una lista de 350 nombres.

Caso distinto fue la del 2 de marzo de 1944, hecha por la Gestapo también, sin que los alemanes hubieran prevenido a la policía, de la que, por cierto, desconfiaban y con razón, de ahí que el número de detenidos fuera de más de 230 judíos.

Es por ello que no podemos dejar pasar por alto la actuación de algunos miembros de dicha policía, como la del Sr. Marie, Secretario de policía y Jefe del servicio de extranjeros, o la de Edouard Vigneron ${ }^{24}$, igualmente Secretario de policía antes que Marie y Jefe del servicio de extranjeros también. Este último hacía carnés de identidad falsos para los judíos, pero fue descubierto, revocado de sus funciones y condenado a tres meses de prisión. Sin la intervención de altos funcionarios de policía que le ayudaron hubiese sido deportado.

No menos importante fue el Sr. François Pinot, Inspector Subjefe, que en la primera redada había prevenido a muchos judíos. Cuestión distinta es el caso del Sr. Schmidt, Prefecto de Meurthe-et-Moselle, que aparentemente pasaba por un colaborador, sin embargo, en 1942, al mismo tiempo que habían detenido a judíos extranjeros también detuvieron a judíos franceses, por lo que por este motivo Schmidt dirigió una carta de protesta al Jefe de la Sicherheitspolizei ${ }^{25}$ y expuso también el asunto al Jefe del gobierno, Ministro y Secretario de Estado, si bien, la Sicherheitspolizei no hizo nada ante esta protesta. Schmidt también

23 Willard, 1946, pp. 2-4.

24 Edouard Vigneron fue nombrado Justo entre las Naciones en enero de 1982 por el Yad Vashem de Jerusalem.

25 Sicherheitspolizei: Agentes de policía de seguridad. 
intervino dos o tres veces en favor de ciertos judíos franceses que habían sido arrestados, pero sin éxito ${ }^{26}$.

\section{Daños causados en los edificios de culto}

Al igual que ocurriera en otras partes, apenas unos días después de la llegada de los alemanes a Nancy (1940), éstos tomaron posesión de la sinagoga, en la que hicieron un centro de aprovisionamiento - a partir de ese momento, los oficios religiosos se celebraban en el Oratorio-. Además, las autoridades alemanas dieron un plazo de 24 horas para poner el templo a su disposición. El Gran Rabino, Paul Haguenahuer, aprovechó este corto período de tiempo para pedir permiso a los dirigentes del Museo Lorrain ${ }^{27}$ y de los archivos departamentales para ver si ellos querían guardar en sus locales los objetos más preciados de culto. La respuesta fue positiva y se añadió una sección judía en dicho museo. La sección contenía numerosos objetos de plata de gran valor utilizados en las ceremonias religiosas. La Torá fue colocada en los archivos departamentales, a los que le pusieron el sello "Arch. Dép." para indicar que ellos eran los propietarios.

El Ayuntamiento, por su parte, autorizó al Gran Rabino a depositar los bancos de la Sinagoga en un local del cementerio del Sur. La falta de transportes y el corto período de tiempo (24 horas) que le habían concedido al Gran Rabino no le permitieron ni transportar todo ni poner en lugar seguro la Torá que muchas de las comunidades judías del Este de Francia le habían confiado a la comunidad de Nancy en el momento de la debacle.

Los daños causados en las instalaciones de la sinagoga por los alemanes durante los cuatro años de ocupación fueron considerables. Los grandes órganos habían quedado totalmente inutilizables. Al igual que las magníficas lámparas del templo, la Menorah (candelabro de siete brazos) había sido robada, así como los bajorrelieves; las vidrieras, rotas, y la mayor parte de los bancos que quedaron habían sido deteriorados, muchos fueron quemados y otros habían desaparecido. Por supuesto, todos los libros religiosos que los fieles dejaron en sus cajones habían sido destrozados o robados. La Torá confiada por las comunidades judías de los alrededores de Nancy había sido vendida por alemanes a un marchante de trapos, en cuya casa la encontraron después de la liberación

26 Willard, 1946, pp. 4-5.

27 El Museo Lorrain se encuentra actualmente en el centro de Nancy y fue fundado en 1850. Dicho museo se instaló en torno al antiguo palacio de los duques de Lorena y de la iglesia de los Cordeleros (Église des Cordeliers). 
en un lamentable estado. La comunidad la había rescatado, pero estaba muy mal, y según las estimaciones hechas por especialistas en la materia, serían necesarios, al menos, tres millones de francos para que el templo recuperase el estado de antes de la guerra.

En cuanto a la casa de oraciones de la comunidad polaca, todo lo que allí se encontraba había sido robado por los alemanes. Desde entonces, los oficios se hacían en un pequeño pabellón de la calle del Puente.

Respecto a la casa de refugio judío en la Plaza de Villers, en el momento de la declaración de la guerra, los internos de ese establecimiento fueron evacuados. La comunidad alojó alrededor de 120 refugiados o expulsados de Alsacia y de Lorena. Después de la redada del 2 de marzo de 1944, las autoridades alemanas se apoderaron del inmueble y arrojaron por la ventana todos los muebles y las ropas.

Los mismos alemanes restauraron el edificio para hacer allí un hospital, pero la liberación de Nancy les impidió ejecutar su proyecto. Desde ese instante, el edificio fue ocupado por las autoridades militares francesas (servicio de Sanidad) y posteriormente fue puesto de nuevo al servicio de la comunidad judía ${ }^{28}$.

\section{Unión General de Israelitas de Francia (U.G.I.F.)}

El 29 de noviembre de 1941, Xavier Vallat creó la Unión General de Israelitas Franceses, según lo exigido por el representante de Adolf Eichmann en Francia, Theodor Dannecker ${ }^{29}$.

El representante de la U.G.I.F. en Nancy era Gustavo Nordon. Las relaciones de los ocupantes con él fueron correctas, sin más. En ocasiones, Nordon obtuvo el apoyo de dichos ocupantes cuando se trataba de gestiones de poca importancia, como, por ejemplo, la autorización concedida a una joven de Lúneville ${ }^{30}$ para dirigirse diariamente a Nancy y poder continuar allí sus estudios. También estaba muy bien considerado por las autoridades francesas.

La conducta de Nordon durante aquellos trágicos años no fue menos importante que la del Gran Rabino Paul Haguenauer, con quien colaboró de lleno y en

28 Willard, 1946, pp. 5-6.

29 Sobre Dannecker puede verse: Steur, C., Theodor Dannecker: Ein Funktionär der Endlösung (Schriften der Bibliothek für Zeitgeschichte), Alemán, 1997. https://www.yadvashem. org/odot_pdf/Microsoft\%20Word\%20-\%206244.pdf. Consultado el 1 de febrero de 2019. https:// spartacus-educational.com/GERdannecker.htm. Consultado el 1 de febrero de 2019.

30 Lúneville: Subprefectura del departamento de Meurthe-et-Moselle. 
plena comunión de ideas. Nordon también se sacrificó deliberadamente por la causa de sus correligionarios. Desde antes de la fundación de la U.G.I.F., instituyó, con la ayuda de su abnegada compañera Berta Nordon y la Sta. Zivy, un servicio de solidaridad. Cuando se creó la U.G.I.F., Nordon fue nombrado delegado regional de dicho organismo; hizo numerosas colectas entre los judíos de Nancy para que permanecieran en su lugar o pasaran a la zona libre. También ayudó a los judíos de Nancy privados de todos sus recursos a causa de las leyes de Vichy, así como a los refugiados de Alsacia y de Lorena ${ }^{31}$.

Todas las semanas, Nordon iba al Centro de detención de Écrouves, donde había numerosos judíos del Este en trámites de ser deportados. Les llevaba paquetes de ropa, víveres, mermeladas y otros dulces. Para ello contó siempre con la ayuda de la Sra. Mathieu, una de las dirigentes de la Cruz Roja que hizo todo lo que humanamente le fue posible para procurarle comida destinada a los internados. El papel de la Sra. Mathieu, sin embargo, fue considerado de forma diversa, porque, al parecer, ella frecuentaba muchos lugares reaccionarios y muy afines a la política de colaboración.

Gustavo Nordon era admirablemente secundado en su tarea por un católico, el Sr. Courtaud, jefe de su casa de comercio. Para él fue un colaborador en todo momento. Nordon tuvo, en numerosas ocasiones, justificaciones para explicar a los alemanes sus viajes y supo salir bien parado siempre. Finalmente, en 1943 se le prohibió viajar en automóvil y fue Courtaud quien le reemplazó. Tanto Courtaud como Nordon se llevaron centenares de cartas de los detenidos dirigidas por los internados a sus familias y que ellos hacían llegar a sus destinos. Pudieron llevar las misivas sin que pasaran por la censura gracias a la complicidad del director del campo, el Sr. Cropsal, antiguo lugarteniente de gendarmería. Éste había sido detenido y estaba preso acusado de malversaciones cometidas a costa de los internados.

El 3 de marzo de 1944, Nordon y su mujer fueron detenidos a la vez que otros judíos de Nancy. Él y el Gran Rabino fueron arrestados los primeros a las 5 de la mañana. A pesar de las numerosas advertencias, Nordon no había querido nunca abandonar a sus correligionarios, pues consideraba que su misión era protegerles. El Sr. Chavarot, Secretario General de la Prefectura y, bajo la ocupación, Jefe de gabinete del Prefecto regional, al parecer, le había prevenido por teléfono la víspera de la redada de que ésta era inminente. Courtaud, por su parte, quien se había enterado de lo que se preparaba por el médico de la prisión, había ofrecido a Nordon alojarse en su casa; pero no lo hizo. Rehusó abandonar 
su domicilio. Chavarot fue siempre un simpatizante de los judíos y, según se dijo, habría podido, con la complicidad del director del campo de detención y del médico del hospital de Toul ${ }^{32}$, hospitalizar en dichos establecimientos durante unas semanas a ciertos israelitas, entre otros a el Sr. Schwab, antiguo alcalde de Épinal ${ }^{33}$, de más de 80 años de edad, y haber podido así librarlos de la deportación.

Nordon también ayudó a numerosos judíos a pasar la línea de demarcación, proporcionándoles falsas cartas de identidad ${ }^{34}$.

\section{Campos de concentración a los que fueron enviados los judios de Nancy}

Todos o casi todos los judíos fueron conducidos al Centro de detención de Écrouves $^{35}$, desde donde, al cabo de cierto tiempo, fueron transferidos al Campo de detención de Drancy ${ }^{36}$, y desde allí, a Alemania. No se ha conocido jamás el lugar de destino de ninguno de ellos.

Es preciso señalar que a finales de julio de 1942, en el Centro de Écrouves se había instalado una sección especial para mujeres, previas instrucciones dadas por el alto cargo alemán al Prefecto de Meurthe-et-Moselle.

32 Toul: Se encuentra en la región de Lorraine (Francia).

33 Épinal: Está en la región de los Vosgos (Francia).

34 Willard, 1946, pp. 6-7.

35 Véase anexos. Una placa en Écrouves recuerda a los 2.000 judíos detenidos a partir del 19 de julio de 1942 en las sucesivas redadas de Nancy y trasladados al Centro de detención de Écrouves antes de su deportación a los campos nazis entre 1942 et 1944.

36 Campo de Drancy: véase anexos. El campo de Drancy se encontraba al noreste de París y fue establecido por los alemanes en agosto de 1941 como un campo de internamiento para los judíos extranjeros en Francia; más tarde se convirtió en el campo principal de detención de los judíos que iban a ser deportados de Francia. Hasta primeros de julio de 1943, el campo estuvo bajo la supervisión de la policía francesa y alemana. Después, los alemanes tomaron el control directo del campo. Sobre Drancy puede consultarse: Calef, N.: "Drancy 1941. Camp de représailles, Drancy la faim". Édité et présenté par Serge Klarsfeld pour le 50e. anniversaire du Camp de Drancy en Le Monde Juif. La Revue du Centre de Documentation Juive Contemporaine, $\mathrm{n}^{\circ} .143$ (Nouvelle série), Paris, 1991, pp. 133-502 (paginación separada en el texto: V-XX, 1-354). Cfr. en Rother, 2005, op. cit., Rajsfus, M.: Drancy, un camp de concentration très ordinaire (nouvelle édition), 1941-1944, édité par le Cherche Midi, 2012. En línea: https://www.cherche-midi.com/ livres/drancy-un-camp-de-concentration-tres-ordinaire-nouvelle-edition. Consultado el 26/1/2018; https://halshs.archives-ouvertes.fr/tel-00362523/document. Consultada 4/2/2018; Fredj, J. et Serge Klarsfeld: Drancy: Un camp d'internement aux portes de Paris, Privat, Paris, 2015. 
Se tiene constancia de que regresaron veinticinco judíos de todos los que fueron deportados (250 franceses), de los cuales veintidós eran de la comunidad polaca y tres, de la francesa ${ }^{37}$.

\section{Conclusiones}

Según Willard ${ }^{38}$, los judíos de Nancy no tuvieron que sufrir malos tratos de parte de la Milicia, dado que la Milicia no entró en acción hasta junio de 1944 $\mathrm{y}$, en ese momento, según dicho autor, había muy pocos judíos en la ciudad (aunque no aporta cifras), aparte de que, como ya se ha dicho, no se detuvo al número de judíos reales que vivían en Nancy durante las redadas llevadas a cabo, habida cuenta de que la mayoría de ellos había huido a la zona no ocupada, por su cuenta o porque fueron avisados los días anteriores. Se sabe que algunos policías colaboraron con los judíos, sin olvidar el papel desempeñado por el Gran Rabino en favor de sus correligionarios. Todo ello explica cómo al comienzo de la guerra, en septiembre de 1939, había 3.800 judíos en Nancy, en 1943 quedaban aproximadamente 357 y, en 1945, al finalizar la contienda, el número de judíos ascendía a 1.280, aunque no ocurriría lo mismo con los judíos deportados de Nancy, pues regresó menos de un tercio. En cuanto a los daños causados a los edificios religiosos durante la ocupación, el saqueo, la profanación y la destrucción estuvieron a la orden del día.

En definitiva, podemos concluir que el cuestionario hallado con la información contenida nos ha permitido reconstruir de forma aproximada parte de la historia de las comunidades judías de Nancy durante la ocupación alemana, contribuyendo por ello al progreso del conocimiento de las mismas, dada la escasez de estudios al respecto, al menos hasta donde sabemos, dejando la puerta abierta a nuevas investigaciones.

\section{Fuentes inéditas}

Willard, Arthur, "Communauté de Nancy”, Archivo Centro Documentación Judía Contemporánea, París, C.D.J.C., XX-13, 1946. 


\section{Bibliografia}

Amipaz-Silber, G., Sephardi Jews in Occupied France. Under The Tyrant's Heel 19401944, Jerusalem, Rubin Mass Ltd., 1995.

Avilés, JuAn, "Lequerica, embajador franquista en París: un testigo de excepción de la derrota de Francia", Madrid, Historia 16, nº. 160, 1989, pp. 12-20.

"Vichy y Madrid. Las relaciones hispano-francesas de junio de 1940 a noviembre 1942". Espacio, Tiempo y Forma, serie V, Historia Contemporánea, $\mathrm{n}^{\circ}$. 2, 1989, pp. 227-239.

AvNi, Haim, "La salvación de judíos por España durante la Segunda Guerra Mundial", en Hassan, J.M. (1970), Madrid, Actas del I Simposio de Estudios sefardies, 1964, pp. 81-89.

España, Franco y los judios, Madrid, Altalena, 1982.

Bauer, Yehuda, American Jewry and the Holocaust: The American Jewish Joint Distribution Committee, 1939-1945, Detroit, 1981.

CAlef, NöEl, “Drancy 1941. Camp de représailles, Drancy la faim”. Édité et présenté par Serge Klarsfeld pour le 50e. anniversaire du camp de Drancy, Le Monde Juif. La Revue du Centre de Documentation Juive Contemporaine, $\mathrm{n}^{\circ} .143$ (Nouvelle série), Paris, 1991, pp. 133-502 (paginación separada en el texto: V-XX, 1-354). Cfr. en Rother, Bernard, Franco y el Holocausto, traducción de Leticia Artiles Gracia, revisión de Gonzalo Álvarez Chillida, Madrid, Marcial Pons, 2005.

Catala, Michel, Les relations franco-espagnoles pendant la Deuxième Guerre Mondiale. Paris, L'Harmattan, 1997.

CAVA, Ma . José, "José Félix de Lequerica, embajador en Francia (1939-1944). El gesto retórico", Propagandistas y diplomáticos al servicio de Franco (1936-1945), (coord.) Antonio César Moreno, Cantano, 2012, pp. 81-120.

Eiroa, Matilde, Las relaciones de Franco con Europa Centro-Oriental (1939-1945), Barcelona, Ariel, 2001.

Fredi, J. et Serge Klarsfeld, Drancy: Un camp d'internement aux portes de Paris, Privat, Paris, 2015.

GildeA, Robert, Combatientes en la sombra. La historia definitiva de la resistencia francesa, Barcelona, Taurus, 2016.

Hilberg, Raúl, La destrucción de los judios europeos, Madrid, Akal, 2005.

Höss, Rudolf, Yo, comandante de Auschwitz, Ediciones B, 2009.

Hyman, Paula E., The Jews of Modern France. Berkeley-Los Angeles-London, University of California Press, 1998.

Job, FrançoIs, Les Juifs de Nancy du XIIeau XXesiècle [compte-rendu]. Archives de Sciences Sociales des Religions, 1997. En línea: https://www.persee.fr/doc/ assr_0335-5985_1997_num_100_1_1181_t1_0099_0000_2. Consultado el 10 de febrero de 2019.

Klarsfeld, Serge, Livre Mémorial de la deportation des Juifs de France, Association des Fils et Filles des Déportés Juifs de France, Paris, 1978. 
Vichy, Auschwitz, Paris, Fayard, 2001.

"La Shoah en France: Le calendrier de la persécution des Juifs de France, juillet 1940-août 1942”, vol. 2. Paris, Fayard, 2001.

"La Shoah en France: Le calendrier de la persécution des Juifs de France, septembre 1942-août 1944", vol. 3. Paris, Fayard, 2001.

Klarsfeld, Serge et Michel Goldberg, L'antisemitisme en toute liberté, Paris, Le bord de l'eau, 2014.

Laffitte, Michel, Juif dans la France allemande, Paris, Tallandier, 2006.

Lisbona, José Antonio, Más allá del deber. La respuesta humanitaria del Servicio Exterior frente al Holocausto, Madrid, Ministerio de Asuntos Exteriores y de Cooperación, 2015.

Marquina, Antonio, "La España de Franco y los judíos", en Uriel Macías Kapón, Yolanda Moreno Koch y Ricardo Izquierdo Benito (coords.), Los judíos en la España contemporánea: historia y visiones, 1898-1998, Cuenca, Universidad de Castilla-La Mancha, 2000, pp. 191-200.

Martín de Pozuelo, Eduardo, El franquismo, cómplice del Holocausto, Barcelona, La Vanguardia, 2012.

Morcillo Rosillo, Matilde, El Cónsul General Bernardo Rolland de Miota y los sefardies de París durante la Segunda Guerra Mundial, Zaragoza, Riopiedras Ediciones, 2016.

Paldiel, Mordecai, Diplomat Heroes of the Holocaust, Jersey City, Ktav Pub., 2007.

Payne, Stanley G., Franco y Hitler. España, Alemania, La Segunda Guerra Mundial y el Holocausto, Madrid, La Esfera de los Libros, 2008.

Poznanski, Renée, Jews in France during World War II, 2011. En línea: https://www. google.es/search?q=ugif\&hl=es\&gbv=2\&prmd=ivns\&ei=43 drWpaiKIW3U aT_uqgD\&start $=10 \& s a=N$. Consultado el 26/1/2018.

ReIn, RaAnAn, Franco, Israel y los judios, Madrid, Consejo Superior de Investigaciones http://www.historiasiglo20.org/BIO/petain.htm. Consultado el 3 de enero de 2018.

Rother, Bernard, Franco y el Holocausto, traducción de Leticia Artiles Gracia, revisión de Gonzalo Álvarez Chillida, Madrid, Marcial Pons, 2005.

SAlinas, David, España, los sefardies y el Tercer Reich (1939-1945). La labor de los diplomáticos españoles contra el genocidio nazi, Valladolid, Universidad de Valladolid-Ministerio de Asuntos Exteriores, 1997.

Toledo, Alain de, “C'est un Juste”, Sepharadinfo, Paris, Aki Estamos, 2010.

Zuccotti, Susan, The Holocaust, the French and the Jews, Nueva York, University of Nebraska Press, 1993. 


\section{A partir du 7 juin, les Juifs porteront UN INSIGNE DISTINCTIF}

Le journal officlel contenant les a la dato preserite s'expesern aux ordonmanees du Mi!itarbefehlshaper in Prankreich publio l'ordonnance cl=apres :

En yartal des plelns pouvolrs qui m'ont átés conférós par lo Fuehrer und oberster Befehlshaber der Wehrmąht, j'erdonas ce quil suit :

1) Il est Interdit aux Juifs, dàs l'âge de slx afas révolus, de pą raitre en publla nans portop l'étolle juive,

2) L'śtolle julye est una étolle à six pointe aysnt les dimensions de la paume d'une main et les contours noirs. Elle est en tIssu jaune et porte, en caractères nolrs, l'inscription đulf a. Elle devra ếtre portée bler visiblement sur le cótó gauche de la poitrine, solidemept cousue sur lo vấtement.

Les infractions a la présente or donnanes serpont punles d'empilsonnement et d'amende ou d'une de ces deux pelnes, Des mesures de pollee, telles que linternement dans un camp de Julfs, pourront s'ajoutey ou être substitués a cẹ peines.

La présente ordennance entrexa en visupur la 7 Jula $194 \%$.

Der Multarbefehlohaber in Frankreieh.

\section{Les modalités du retrait} de l'insigne spécial des Juifв

Lą profecture de police commuv nigue :

En vue de se canfermer à la hultionas ardonuanee de l'autorité divesupation ca data du entre en vigueup le Juin, les julfs hompas et tammes antralnts au pert de linsigne spécial devront le rativer pblisatolrement au commissarlat de leur quartlas ou do leur alrconseription aux dates of dans p'ordre cl-apress t

dulfs dent les noms commeneent par le leţtrea cl-après I

A ou B . 2 mardi 2 Jula; 0 A $\mathbf{~} \mathbf{m}$ -

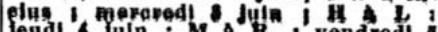
Jn, s a $z$,

Ils devront etre pontour.

Ils devront etre popteurs de lpyp

carte d'identité ot do leur carte da

eines prévlues par l'ordonnanee. Tous les julth visés par la meure deviont, on effet, atre mual de leur Insigne la f juln as plus ard.

\section{AVIS}

Les Juifs goumis a l'obligation de portep un olgne d/s tinctif en vertu de la $8^{\circ}$ ordon. nance du 29 mai 1942 sur les mesures prisess gontre les julfs deveront be présentep au commissarlat de po!tce ou à la sous-préfecture de leur domielle pour y reeevolr les insignes en farme d'étoila prévus au paragraphe premlef $\mathrm{de}$ ladite ordonnance. Chaque juif rece. vFa trois insignes et devra donner en échange up polnt de sa earte de textile.

Lo chef superieur do la police et des 8. 8. dispendaut du Mulitierbefenlskaber on Eranos,

\footnotetext{
ruta
}

Fuente: Archivo Ministerio Asuntos Exteriores (Madrid), R. Legajo 1.716 


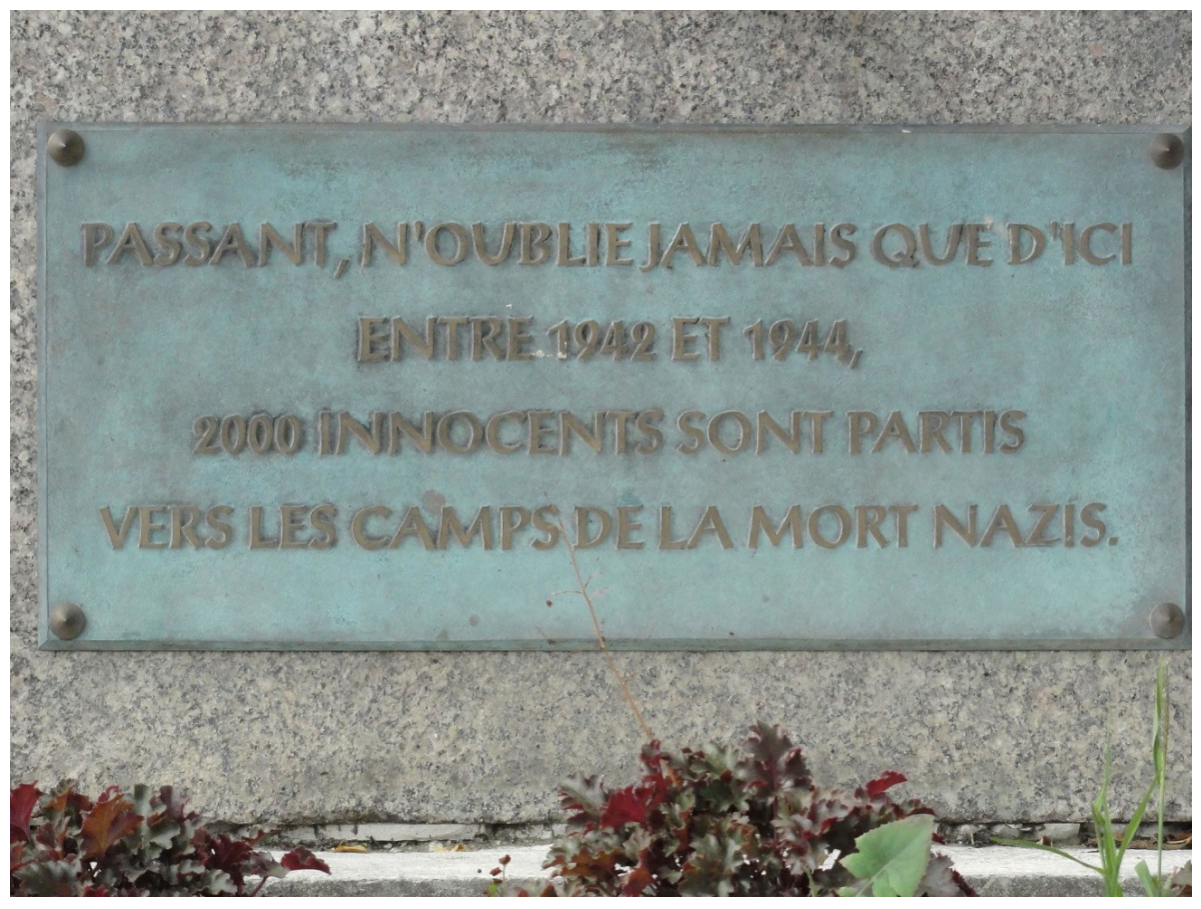

Placa conmemorativa de los judíos deportados de Nancy

Fuente: https://fr.wikipedia.org/wiki/Écrouves 


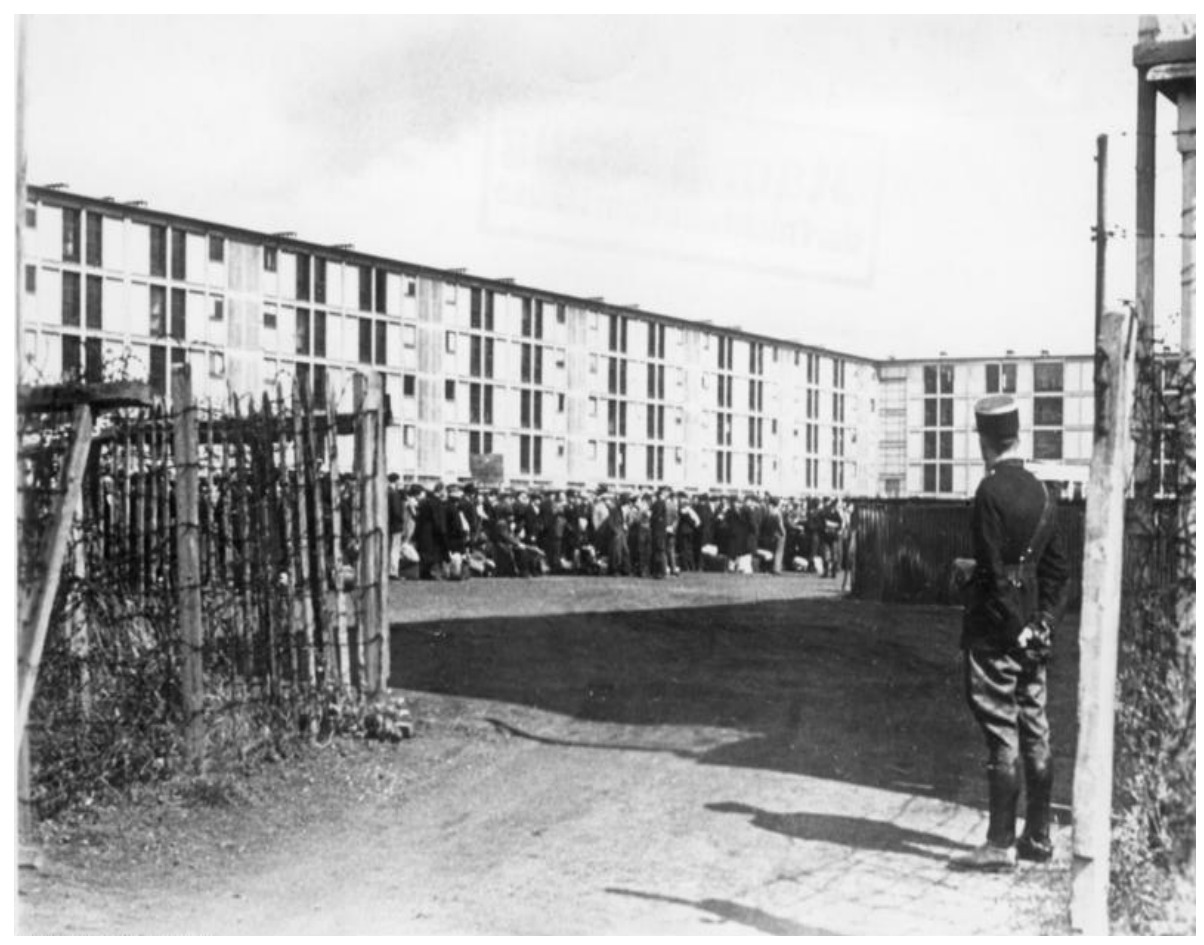

Campo de Drancy

Fuente: https://en.wikipedia.org/wiki/Vel\%27_d\%27Hiv_Roundup 


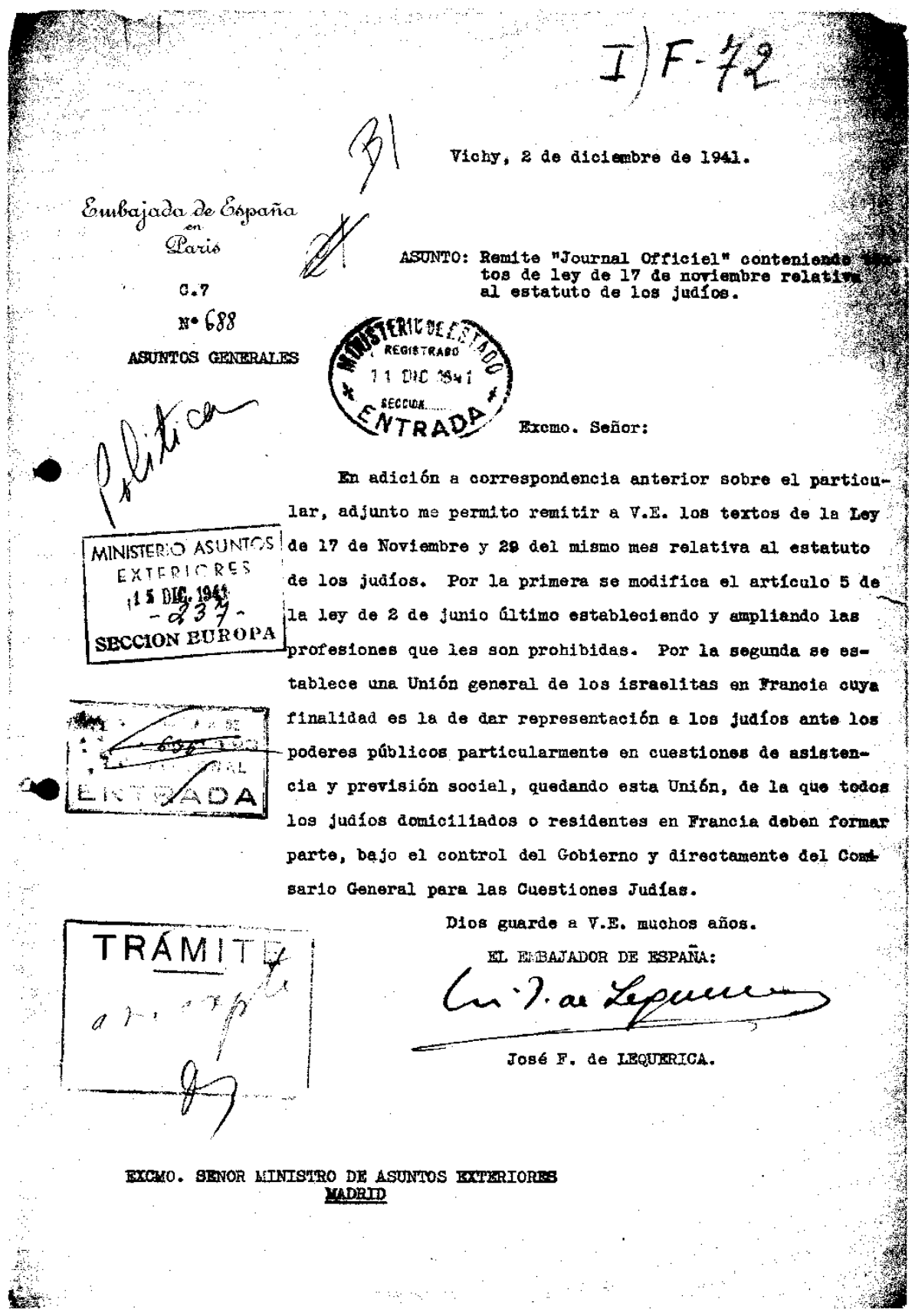

Fuente: Archivo Ministerio Asuntos Exteriores (Madrid), R. legajo 1.716 